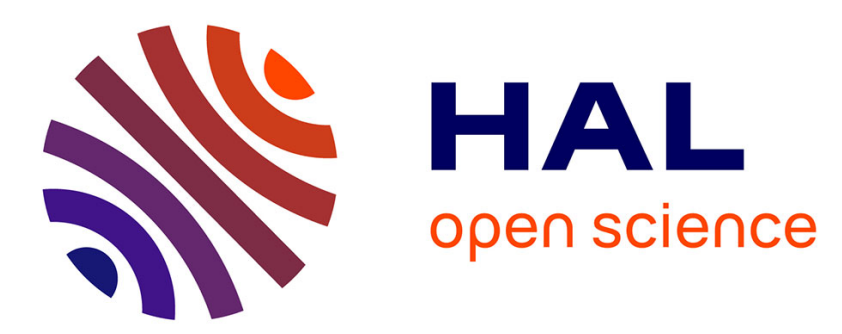

\title{
Rheological behaviour of wormlike micelles : effect of salt content
}

\author{
S. Candau, A. Khatory, F. Lequeux, F. Kern
}

\section{To cite this version:}

S. Candau, A. Khatory, F. Lequeux, F. Kern. Rheological behaviour of wormlike micelles: effect of salt content. Journal de Physique IV Proceedings, 1993, 03 (C1), pp.C1-197-C1-209. 10.1051/jp4:1993117 . jpa-00251560

\section{HAL Id: jpa-00251560 https://hal.science/jpa-00251560}

Submitted on 1 Jan 1993

HAL is a multi-disciplinary open access archive for the deposit and dissemination of scientific research documents, whether they are published or not. The documents may come from teaching and research institutions in France or abroad, or from public or private research centers.
L'archive ouverte pluridisciplinaire HAL, est destinée au dépôt et à la diffusion de documents scientifiques de niveau recherche, publiés ou non, émanant des établissements d'enseignement et de recherche français ou étrangers, des laboratoires publics ou privés. 


\title{
Rheological behaviour of wormlike micelles: effect of salt content
}

\author{
S.J. CANDAU, A. KHATORY, F. LEQUEUX and F. KERN
}

Laboratoire d'Ultrasons et de Dynamique des Fluides Complexes, Unité de Recherche Associée au CNRS 851, Université Louis Pasteur, 4 rue Blaise Pascal, 67070 Strasbourg cedex, France

\begin{abstract}
We study the effect of salt content on the rheological properties of wormlike micelles formed from hexadecyltrimethylammonium bromide (CTAB) in presence of potassium bromide $(\mathrm{KBr})$ and of cetylpyridinium chlorate $\left(\mathrm{CPClO}_{3}\right)$ in presence of sodium chlorate $\left(\mathrm{ClO}_{3} \mathrm{Na}\right)$. Upon increasing the salt concentration, at fixed surfactant concentration, we observe for both systems a maximum of the zero-shear viscosity $\eta_{0}$. For salt concentrations less than that corresponding to the maximum of $\eta_{0}$, the variation of $\eta_{0}$ with the surfactant concentration $C$ can be described by a reptation model. Beyond the maximum, the scaling laws obtained for $\eta_{0}(C)$ are characterized by values of the exponent much smaller than those predicted by the existing theoretical models. The results are qualitatively interpreted by a description based on a structural evolution upon increasing salt content from a system of entangled linear micelles to a multiconnected network. Measurements of the plateau modulus of CTAB solutions, as a function of $\mathrm{KBr}$, give results supporting the above hypothesis.
\end{abstract}

Résumé

Nous présentons une étude de l'influence de la teneur en sel sur les propriétés rhéologiques de solutions de micelles cylindriques formées à partir de bromure d'hexadecyltrimethylammonium (CTAB) en présence de bromure de potassium (KBr) et de chlorate de cetylpyridinium $\left(\mathrm{CPClO}_{3}\right)$ en présence de chlorate de sodium $\left(\mathrm{ClO}_{3} \mathrm{Na}\right)$. Lorsqu'on fait varier la concentration en sel, à concentration en tensioactif constante, on observe pour les deux systèmes un maximum de la viscosité à gradient nul $\eta_{0}$. Pour des concentrations en sel inférieures à celle correspondant au maximum de $\eta_{0}$ la variation de $\eta_{0}$ avec la concentration en tensioactif $C$ peut être décrite par un modèle de reptation. Au-delà du maximum les lois d'échelles obtenues pour $\eta_{0}(C)$ sont caractérisées par des valeurs de l'exposant beaucoup plus faibles que celles prédites par les modèles théoriques existants. Les résultats sont interprétés qualitativement à partir d'une description fondée sur l'évolution de la structure micellaire lorsqu'on augmente la teneur en sel, d'un système de micelles linéaires enchevêtrées vers un réseau interconnecté. Les mesures du plateau du module de cisaillement en fonction de la concentration en $\mathrm{KBr}$ pour des solutions de $\mathrm{CTAB}$ donnent des résultats étayant cette hypothèse. 


\section{Introduction}

Under appropriate conditions of concentration, salinity, temperature, presence of counterions, etc., the amphiphiles are found to assemble reversibly into long, flexible wormlike micelles that can form a viscoelastic fluid reminiscent of an entangled polymer solution (1). Strong evidence of such an analogy for several aqueous cationic surfactants in the presence of salt has been reported in the last years (1-5).

The viscoelastic properties of solutions of flexible and entangled micelles have been extensively studied both theoretically $(1,6,7,8)$ and experimentally $(9-17)$. It is now recognized that the reversible breaking down of elongated micelles can have an important influence on the viscoelastic properties of these systems.

A simple theoretical model, based on the reptation theory which describes the rheological properties of entangled polymeric chains, has been derived by Cates (6). This model predicts several rheological regimes depending on the relative rates of diffusive polymer motion and reversible breakdown processes. In particular, a nearly single exponential stress decay function is predicted in the linear viscoelastic response, in the limit where the micelle breaking time is short compared to the reptation time of a micelle of length equal to the average micellar length.

Such a behavior was observed for several systems (9-17). Furthermore, the Cates model used in conjunction with the theoretical predictions for the micellar growth based on mean-field models $(1,7,18,19)$ leads to scaling laws for the zero shear viscosity, the terminal time of the stress relaxation and the self-diffusion coefficient as a function of the surfactant concentration. Experimental results obtained for hexadecyltrimethylammonium bromide (CTAB) solutions in aqueous $\mathrm{KBr}$ solutions are satisfactorily accounted for by the model $(9,20)$. However the observed behaviour is not universal. It was found that, if the amount of added salt is insufficient to screen out the electrostatic interactions, the variations of the rheological parameters with surfactant concentration were larger than expected theoretically $(2,20)$. This was interpreted as the result of abrupt increase of micellar size resulting from electrostatic interactions (21). At the opposite, it was shown recently that solutions of cetylpyridinium chlorate $\left(\mathrm{CPClO}_{3}\right)$ in sodium chlorate $\left(\mathrm{ClO}_{3} \mathrm{Na}\right)$ brine, even though they form extremely long wormlike micelles, exhibit an amazingly high fluidity that cannot be accounted for by the reptation model (22). It was suggested that this behaviour could be due to the formation of crosslinks between micelles leading to a solution of entangled branched micelles or even to a multiconnected network (23) (cf. Fig.1). Such a possibility was suggested by Porte et al. (23) to explain some phase separations observed in wormlike micellar solutions.

A statistical description of the occurrence of crosslinks versus entanglements in semi-dilute solutions of wormlike micelles has recently been proposed (24). 
In this paper we report on a systematic study of the effect of salt content on the zero shear viscosity behaviour for two systems : $\mathrm{CTAB} / \mathrm{KBr}$ and $\mathrm{CPClO}_{3} / \mathrm{ClO}_{3} \mathrm{Na}$. The results suggest a structural variation of the system upon increasing the salt content from an entangled solution to a multiconnected network.

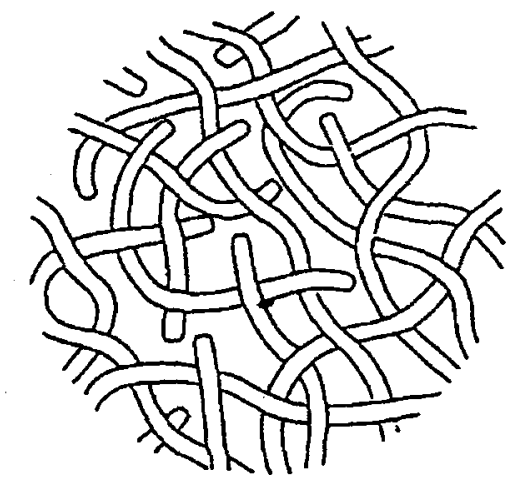

(a)

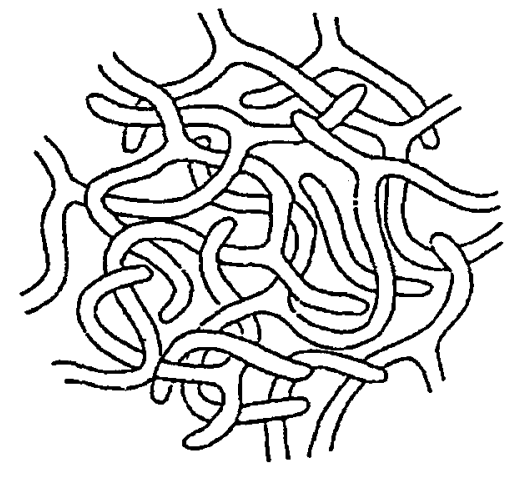

(b)

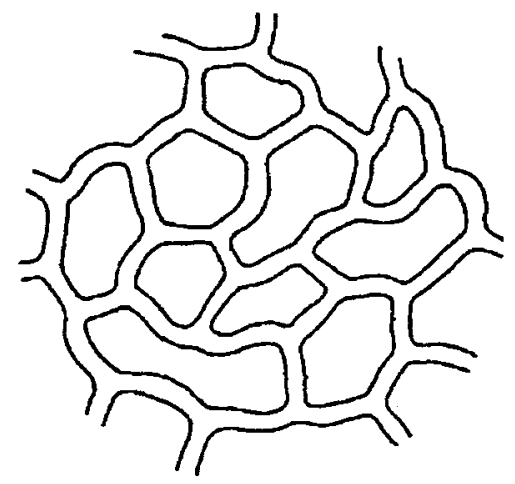

(c)

Figure 1. Possible evolution of the structure of systems of wormlike micelles upon increasing salt content . (a) Entangled linear micelles (b) Entangled branched micelles (c) Multiconnected saturated network.

\section{Theory}

The main features of the theoretical models describing both equilibrium and dynamic properties of wormlike micelles can be found in ref.1. Here we simply recall the theoretical results that are needed to discuss our experiments, more specifically regarding the effect of surfactant concentration on the zero-shear viscosity. 
Mean-field models (17-19) predict that the number density of elongated micelles is exponential with some mean length $\bar{L}$ given by : ( $\vec{L}$ being expressed in monomer units)

$$
\begin{gathered}
C_{0}(L) \sim \frac{1}{\bar{L}^{2}} \exp (-L / \bar{L}) \\
\text { with } \bar{L} \sim C^{1 / 2} \exp \left(E_{\text {sciss }} / 2 k_{B} T\right)
\end{gathered}
$$

where $C$ is the surfactant concentration and $E_{\text {sciss }}$ is the scission energy of the micelle that represents the excess free energy for a pair of hemispherical endcaps relative to a rodlike region containing an equal number of surfactants (19). The above relationships have been derived for nonionic micelles or ionic micelles at large ionic strength. A model calculation for semidilute elongated micellar solutions with no added salt was recently proposed (21). This model suggests that Coulomb interactions results in an additional contribution to the free energy of an endcap that depends logarithmically on $C$. This modifies the growth law for $\bar{L}$ which now varies approximately, if we consider a relatively narrow range of $C$ (about 1 decade), as $C^{(1 / 2)(1+\Lambda)}$ where $\Lambda>0$ depends on the renormalized Coulomb charge of an endcap. The physical origin of the increased growth exponent is that the electrostatic free energy contributions favor hemispherical endcaps over the cylindrical regions. The same effect leads to smaller micelles for a fixed $C(25,26)$.

It is generally assumed that the chemical relaxation proceeds through reversible unimolecular scission, characterized by a breaking time $\tau_{\text {break }}$ :

$$
\tau_{\text {break }}=(k \bar{L})^{-1}
$$

where $k$ is a rate constant.

The modified reptation model developed by Cates predicts that in the limit $\tau_{\text {break }} / \tau_{\text {rep }} \ll 1$ the stress relaxation is described by a single exponential decay with the relaxation time $T_{R}$ given by :

$$
T_{R} \simeq\left(\tau_{\text {break }} \tau_{\text {rep }}\right)^{1 / 2}
$$

$\tau_{r e p}$ is the reptation time of a micelle of the mean length given by:

$$
\tau_{\text {rep }} \sim \vec{L}^{3} C^{3 / 2}
$$

The zero-shear viscosity $\eta_{0}$ is related to the terminal time and the plateau modulus $G_{\mathrm{e}}$ through

$$
\eta_{0}=G_{e} T_{R}
$$

For semi-dilute solutions it has been shown that (27)

$$
\begin{gathered}
G_{e} \sim k_{B} T C^{b} \\
\text { with } b=2-2.3 .
\end{gathered}
$$

Combining eqs. 2 to 7 leads to the following behaviour of the zero-shear viscosity : 


$$
\eta_{0} \sim C^{3.25-3.55}
$$

Some experimental results were found to be in good agreement with the above predictions $(9,16,17)$. However, for some systems the exponent of the scaling law $\eta_{0}$ versus $C$ is found significantly larger than the above predicted value. This occurs in the two following cases :

i) $\tau_{\text {break }} / \tau_{\text {rep }} \gg 1$. In that case, the rheological behaviour is described by the classical reptation model of ordinary polymers.

As the distribution of micellar lengths is quite broad (cf. Eq.1), the stress relaxation $\sigma(t)$ is characterized by an extremely non exponential decay :

$$
\sigma(t) \sim \exp \left[-\left(t / \tau_{\text {rep }}\right)^{1 / 4}\right]
$$

The zero-shear viscosity is found to scale with $C$ according to :

$$
\eta_{0} \sim C^{5-5.3}
$$

ii) The screening of the electrostatic interactions is insufficient, which, as said above, produces an enhancement of the micellar growth.

It must be noted that both effects can occur simultaneously as a lower salt content generally leads to smaller micelles and therefore to a shorter $\tau_{\text {rep }}$ and, according to eq. 3 to a longer breaking time.

The exponent of the scaling law of $\eta_{0}$ versus $C$ can also be lower than 3.5 if the breaking time is short enough that the dominant chain motion on that time scale is not reptation but local chain motion ("breathing" or Rouse modes) (6), but in any case, it cannot be lower than 2.

\section{Materials and Methods}

The $\mathrm{CTAB}$ and $\mathrm{CPClO}_{3}$ samples were the same as in our previous investigations $(9,16,17,22)$. The rheological experiments were performed on a Carrimed CSL 100 apparatus (controlled stress) using stainless steel Couette, cone-plane, plane-plane geometries. For the Couette cell, the inner radius was $1.38 \mathrm{~cm}$, the outer radius $1.5 \mathrm{~cm}$, the immersed height $3.2 \mathrm{~cm}$ and the sample volume approximately $9 \mathrm{~cm}^{3}$. The cone angle was $4^{\circ}$, the diameter of the cone and planes $4 \mathrm{~cm}$. Special devices were used to avoid evaporation. Both oscillatory and flow experiments, respectively up to $10 \mathrm{~Hz}$ and $500 \mathrm{~s}^{-1}$ were performed at a temperature of $35^{\circ} \mathrm{C}$. The zero-shear viscosity was obtained by extrapolation to zero frequency for CTAB samples and by extrapolation to zero shear for $\mathrm{CPClO}_{3}$ samples.

\section{$\underline{\text { Results and discussion }}$}

The two investigated systems, $\mathrm{CTAB} / \mathrm{KBr}$ and $\mathrm{CPClO}_{3} / \mathrm{ClO}_{3} \mathrm{Na}$ exhibit quite different rheological behaviours. Experiments performed at various shear rates indicate that all CTAB solutions behave as strongly non-newtonian liquids whereas the $\mathrm{CPClO}_{3}$ solutions are newtonian except those with high 
surfactant concentration $(0.26 \underline{\mathrm{M}})$ and with salt content ranging from $0.02 \underline{\mathrm{M}}$ to $0.4 \underline{\mathrm{M}}$ (Figure 2). Also oscillatory measurements show that the CTAB solutions are viscoelastic, whereas no frequency dependence of the viscosity was observed in all investigated $\mathrm{CPClO}_{3}$ systems. This implies that the terminal time of the stress relaxation of CTAB systems is larger by at least one order of magnitude than the one of $\mathrm{CPClO}_{3}$ solutions.

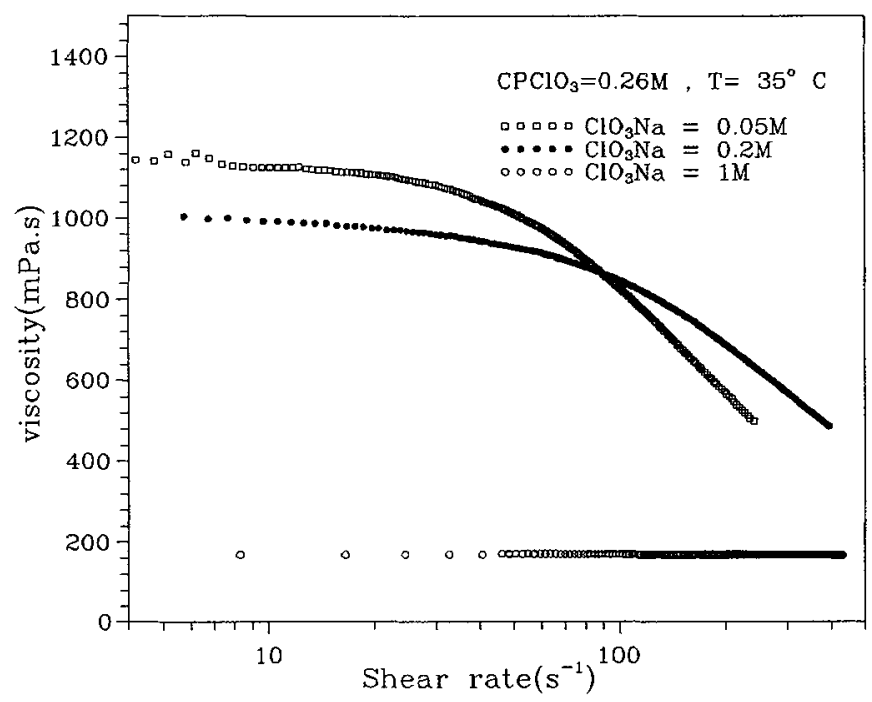

Figure 2. Variations of the viscosity as a function of the shear rate.

In figure 3 are reported the variations of the zero-shear viscosity as a function of salt concentration for CTAB solutions at $C=0.35 \underline{\mathrm{M}}$ and $\mathrm{CPClO}_{3}$ solutions at $C=0.26 \underline{\mathrm{M}}$. In both cases one observes a maximum of viscosity but the amplitudes of the maxima differ by two orders of magnitude. According to eqs. 2 to 6 the zero-shear viscosity at a given surfactant concentration depends on $\bar{L}$ and $k$ according to :

$$
\eta_{0} \sim G_{e} C^{3 / 4} \bar{L} k^{-1 / 2}
$$

The mean micellar length $\bar{L}$ can be varied by varying the salt concentration. It is generally admitted that increasing the salt concentration amounts to increase the curvature energy of surfactant molecules in the end-cap relative to the one in the cylindrical body of the micelle. This leads to an increase in micellar length (cf. Eq.2) and hence in the zero-shear viscosity. Therefore, the decrease of viscosity observed at high salt content in figure 3 would reflect, in the framework of the reptation model, a strong increase 


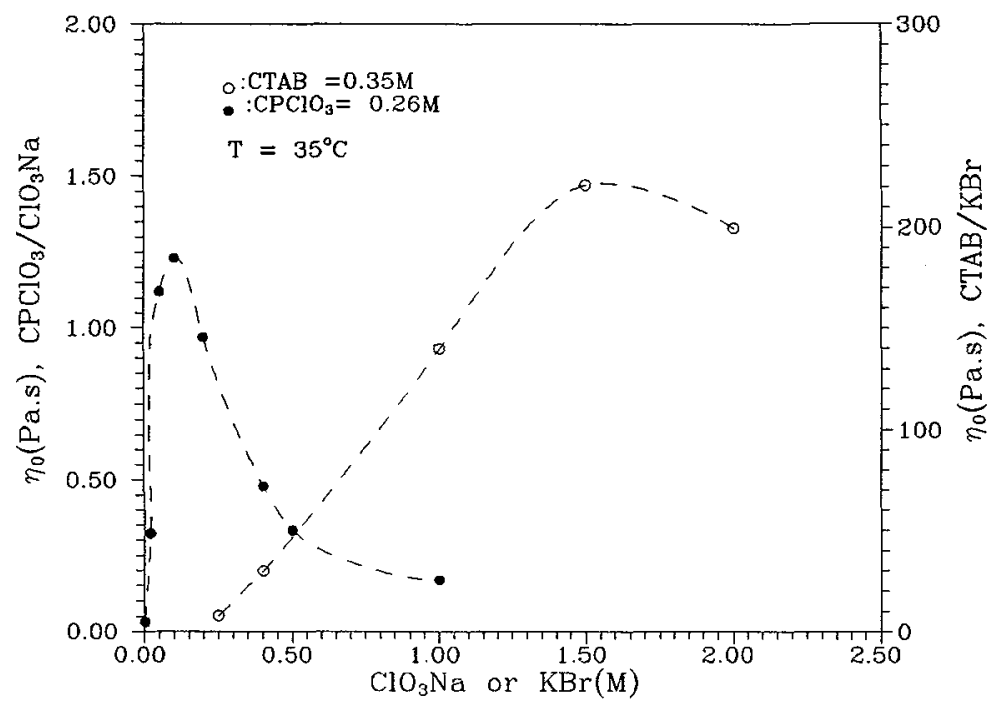

Figure 3. Variations of the zero shear viscosity as a function of the salt concentration at fixed surfactant concentration. The lines are guides for eyes.

of the rate constant $k$ upon increasing the salt concentration. However, as explained further, this is not consistent with the $C$ dependence of $\eta_{0}$. Another mechanism can be proposed, based on the formation of equilibrium crosslinks arising through local fusion of micelles $(22,24)$. In this respect, it should be noted that any change of conditions that increases the end-cap energy should decrease the energy required to form a cross-link in which the curvature change has opposite sense to that of an endcap. A recent model of reptation of branched micelles undergoing reversible scission shows that the viscosity is reduced with respect to that of entangled linear micelles (28). Contrary to the case of ordinary branched polymers where the branch points have fixed positions along the chemical sequence, here the connections can slide along the cylindrical part of the micelles. The sliding connections increase the diffusion rate of the cylindrical part of the micelles within their tube : this comes from the high number of degrees of freedom in the reptation process, compared to the case of classical polymer. This effect, combined with the scission recombination mechanism, leads to a reduction of the viscosity. Also in the limit of many connections, the micelles can make a multiconnected saturated network (cf. Figure.1c). In such networks there are no entanglements and therefore, a new mechanism for the relaxation of stress, involving only the sliding of crosslinks along the cylindrical micelles, becomes possible (22). Such a mechanism can account for a much lower viscosity than the reptation-breaking process. An analogy can be drawn here with the highly fluid $L_{3}$ phase where a multiconnected fluid membrane separates two identical subspaces of solvent (29). 
Figure 4 shows in a log-log representation, the variations of the zero shear viscosity of $\mathrm{CPClO}_{3}$ solutions as a function of surfactant concentration for various salt concentrations. The curves show a net break that corresponds to the cross-over $C^{*}$ between dilute and semi-dilute regimes. In the semidilute regime the variation of the zero shear viscosity with $C$ can be satisfactorily described by a power law with an exponent $a$. Such a behavior was already observed for other micellar systems $(9,16,17,30,31)$.

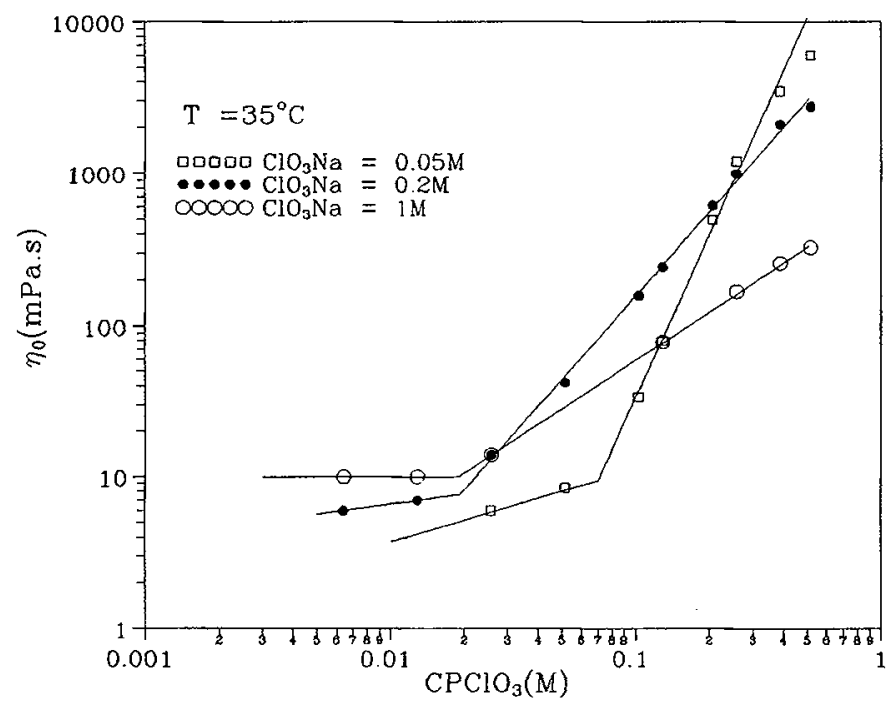

Figure 4. Variations of the zero shear viscosity of the $\mathrm{CPClO}_{3}$ solutions as a function of $\mathrm{CPClO}_{3}$ concentration.

In figure 5 we have reported the variations of $C^{*}$ and $a$ with the salt concentration. The monotonous decrease of $\mathrm{C}^{*}$ upon increasing $\left[\mathrm{ClO}_{3} \mathrm{Na}\right]$ reflects the increase in micellar length which is the expected behavior.

By contrast, the observed decrease of the exponent $a$ from 5 to 1 as $\left[\mathrm{ClO}_{3} \mathrm{Na}\right]$ varies from $0.02 \mathrm{M}$ to $1 \mathrm{M}$ is quite unexpected. In the regime of low salt concentrations, values of $a$ of the order of 5 can be associated with a classical reptation regime or/and an effect of the electrostatic interactions. At the opposite, in the regime of high salt concentrations, values of $a$ as small as 1 cannot be explained by any mechanism based on the reptation model of entangled linear micelles. The decrease of the exponent $a$ upon increasing salt content is also observed for CTAB solutions (Figure 6). This system being strongly viscoelastic, it is possible to measure the stress relaxation. The latter was found to deviate only 


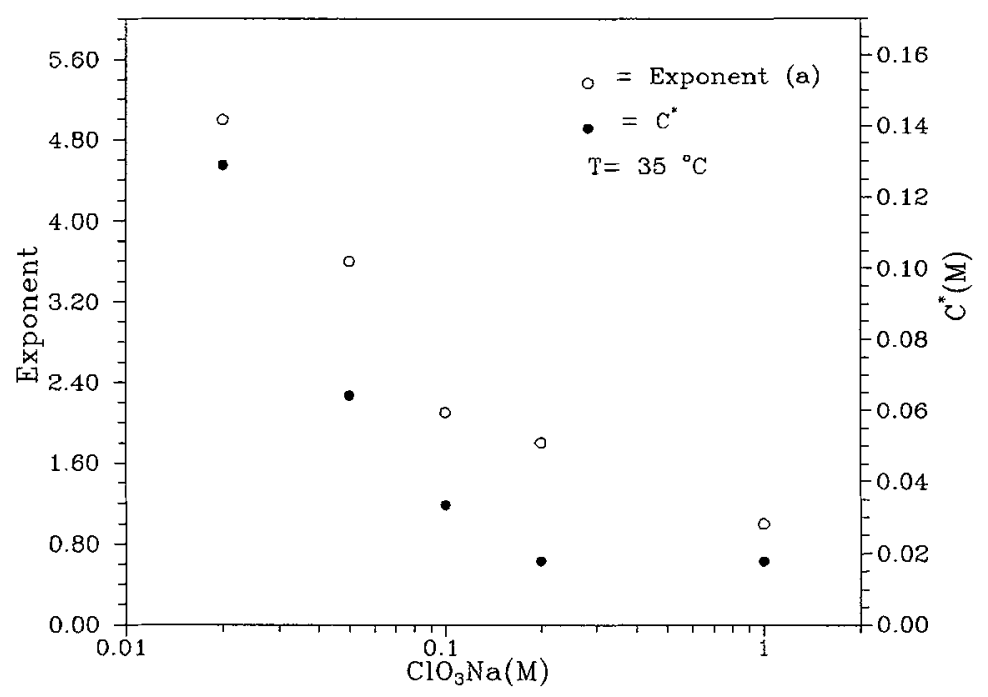

Figure 5. Effect of salt content on the exponent of the scaling law $\eta_{0} \sim \mathbf{C}^{\mathrm{a}}$ and on the crossover concentration $\mathrm{C}^{*}$ for the system $\mathrm{CPClO}_{3} / \mathrm{ClO}_{3} \mathrm{Na}$.

slightly from the exponential behaviour(31), which ensures that the viscoelastic behaviour is not described by Eq. 9, characteristic of the classical reptation process. Therefore the high value of the exponent obtained in the presence of $0.1 \underline{\mathrm{M}} \mathrm{KBr}$ must be attributed to the effect of electrostatic interactions. These interactions play also a major role for the $\mathrm{CPClO}_{3}$ systems as shown by experiments performed in presence of both $\mathrm{ClO}_{3} \mathrm{Na}$ and $\mathrm{NaCl}$. The latter salt doesn't promote micellar growth, but allows to screen out the electrostatic interactions. It was found that for solutions containing $0.02 \underline{\mathrm{M}}$ $\mathrm{ClO}_{3} \mathrm{Na}$ and $0.2 \mathrm{M} \mathrm{NaCl}$, the exponent $a$ was equal to 3.5 (instead of 5 in the absence of $\mathrm{NaCl}$ ), that is the exponent predicted by Eq.8.

At high salt concentration, the variation of $\eta_{0}$ with $C$ for both systems is smaller than predicted by Eq. 8. A model of partial crosslinked micellar network with an increasingly larger number of crosslinks upon an increase of salt concentration can possibly take into account the experimental observations. Referring back to equation 6 relating the zero-shear viscosity to the plateau modulus and to the terminal time of the stress relaxation it must be noted that these two latter parameters can be sensitive to the presence of crosslinks and therefore lead to a concentration dependence of $\eta_{0}$ significantly smaller than that for linear micelles. 


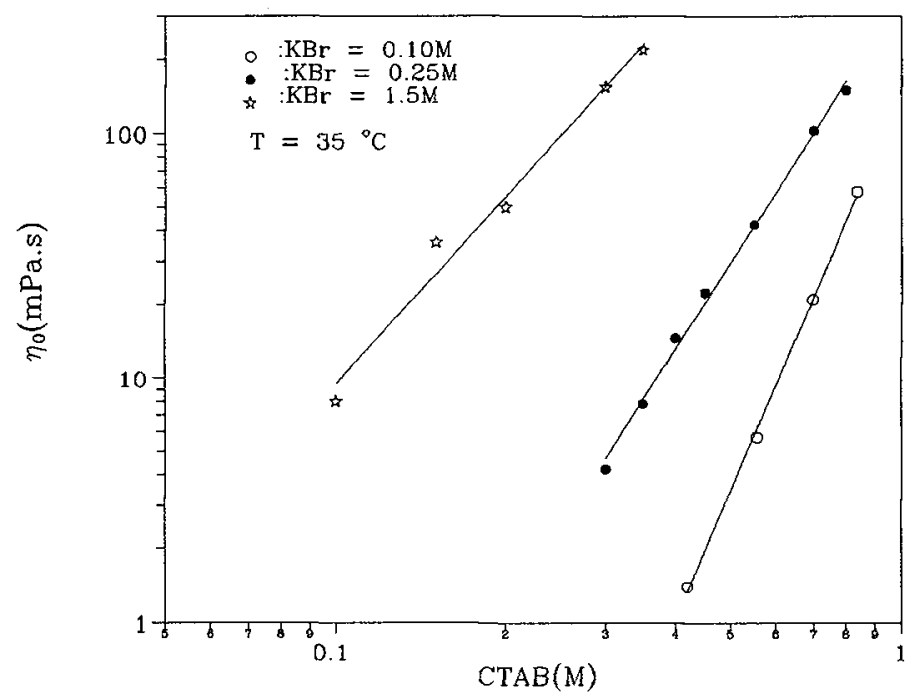

Figure 6. Variations of the zero shear viscosity as a function of CTAB concentration. The slopes of the straight lines, representing the best fits to the data are respectively $5.42(0.1 \mathrm{M} \mathrm{KBr}), 3.63(0.25 \mathrm{M} \mathrm{KBr})$, 2.55 (1.5M KBr).

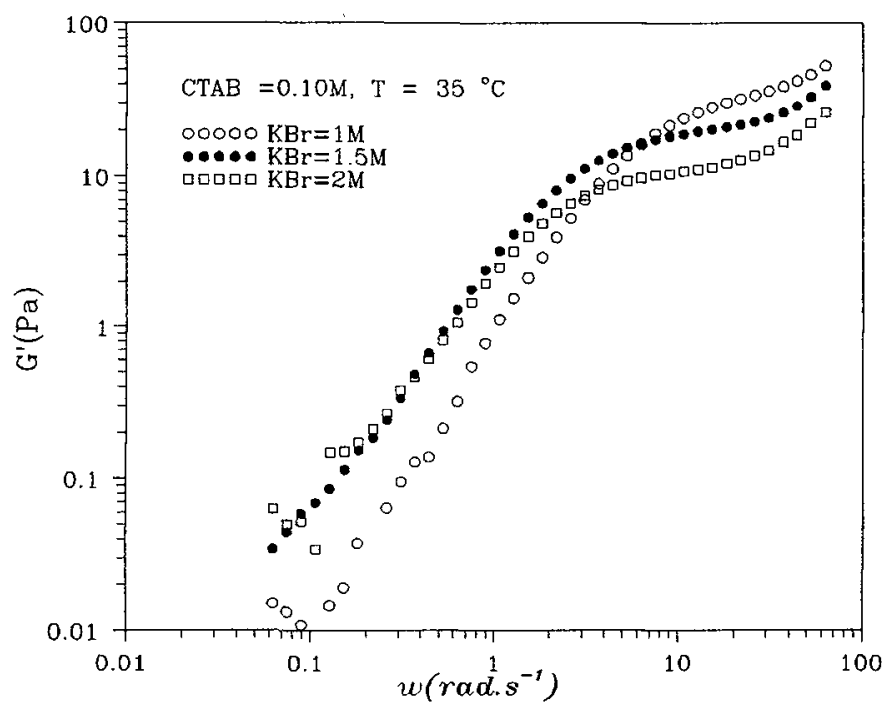

Figure 7. Variations of the real part of the shear modulus as a function of the angular frequency.

The viscosity of $\mathrm{CPClO}_{3} / \mathrm{ClO}_{3} \mathrm{Na}$ systems is too small to allow for a measurement of the plateau modulus $G_{e}$ in the available range of frequencies. Such measurements are however possible in $\mathrm{CTAB} / \mathrm{KBr}$ systems. Figure 7 shows the variation of the real part $G^{\prime}$ of the shear modulus as a function 
of the angular frequency for three solutions of CTAB at a surfactant concentration $0.1 \underline{\mathrm{M}}$ and salt concentrations equal respectively to $1 \underline{\mathrm{M}}, 1,5 \underline{\mathrm{M}}, 2 \underline{\mathrm{M}}$. In the high frequency range, one observes a pseudo-plateau followed by a turn-up of $G^{\prime}$, that is attributed to the occurrence of local Rouse motion (32). The interesting finding here is that the plateau modulus decreases upon increasing salt concentration contrary to what is predicted by the model for entangled micelles, namely that the plateau modulus depends only on surfactant concentration (cf. Eq.7). As a matter of fact, the above theoretical prediction was verified for other micellar systems, with lower salt contents $(9,11,12,16)$. Here the decrease of $G_{e}$ as the salt concentration is increased, likely reflects a progressive replacement of entanglements by crosslinks.

\section{Conclusion}

The results presented in this paper show that the dynamical properties of solutions of wormlike micelles are very sensitive to the salt content. This cannot be interpreted only in terms of variation of the average micellar length, that is found to decrease monotonously upon increasing the salt concentration as inferred from the $C^{*}$ measurements. The most likely explanation to the observed decrease of the scaling law exponent for $\eta_{0}(C)$, as the salt concentration is increased, lies in a structural change where crosslinks are formed, resulting from local fusion of micelles. These crosslinks can be transient with a very short life-time in which case the micelles could cross each other almost freely then conferring to these systems a high fluidity. They can also be equilibrium crosslinks in which case the high fluidity would result from a sliding of the crosslinks. Results, both theoretical and experimental, on the linear and non linear viscoelasticity of CTAB systems at high salt content will be reported shortly.

One would expect that the behaviour of the zero-shear viscosity as a function of the salt concentration, observed for the $\mathrm{CTAB} / \mathrm{KBr}$ and $\mathrm{CPClO}_{3} / \mathrm{ClO}_{3} \mathrm{Na}$ systems, be universal. However, systems with salicylate or alkylbenzoate counterions show a more complex behaviour. For these systems, the curve representing the variation of the zero shear viscosity as a function of salt concentration exhibits two maxima (12). This result can be related to the specific interactions between the surfactant and the counterions that form complexes. For instance, the CTAB and salicylate ions form 1-1 complexes (10). At high salt concentrations, the micelles become negatively charged due to the dominating counterion condensation (33). Then, the effect of Coulomb interactions produces a decrease of micellar length and therefore a lower viscosity. This decrease of micellar length in presence of large amount of counterions has been verified by light scattering on $\mathrm{CPCl} / \mathrm{NaSal}$ systems (34).

Acknowledgement. The authors thank J.APPELL and G.PORTE for providing the $\mathrm{CPClO}_{3}$ sample and for useful discussions. 


\section{REFERENCES}

(1) CATES, M.E., CANDAU, S.J., J. Phys. Condens. Matter 2 (1990) 6869.

(2) CANDAU, S.J., HIRSCH, E., ZANA, R., in "Physics of Complex and Supermolecular Fluids", Safran, S., Clark, N., Eds.; Wiley : New York, (1987) 569.

(3) MAKHLOUFI, R., HIRSCH, E., CANDAU, S.J., BINANA-LIMBELE, W., ZANA, R., J. Phys. Chem. 93 (1989) 8095, and references therein.

(4) JINDAL, V., KALUS, J., PILSI, H., HOFFMANN, H., LINDNER, P., J. Phys. Chem. 94 (1990) 3129, and references therein.

(5) PORTE, G., APPELL, J., Europhys. Lett. 12 (1990) 190.

(6) CATES, M.E., Macromolecules 20 (1987) 2289 ; Europhys. Lett. 4 (1987) 497 ; J. Phys. (Paris) 49 (1988) 1593 ; J. Phys. Chem. 94 (1990) 371.

(7) TURNER, M.S., CATES, M.E., Europhys. Lett. 11 (1990) 681.

(8) TURNER, M.S., CATES, M.E., J. Phys. (Paris) 51 (1990) 977.

(9) CANDAU, S.J., HIRSCH, E., ZANA, R., DELSANTI, M., Langmuir 5 (1989) 1225.

(10) SHIKATA, T., HIRATA, H., KOTAKA, T., Langmuir 3 (1987) 1081 ; 4 (1988) 354 ; 5 (1989) 398.

(11) SHIKATA, T., HIRATA, H., TAKATORI, E., OSAKI, K., J. Non-Newtonian Fluid Mech. 28 (1988) 171.

(12) REHAGE, H., HOFFMANN, H., J. Phys. Chem. 92 (1988) 4712.

(13) HOFFMANN, H., LÖBL, H., REHAGE, H., WÜNDERLICH, I., Tenside Deterg. 22 (1985) 290.

(14) THURN, H., LÖBL, M., HOFFMANN, H., J. Phys. Chem., 89 (1985) 517.

(15) (a) HOFFMANN, H., PLATZ, G., REHAGE, H., SCHORR, W., Ber. Bunsen-Ges. Phys. Chem. 25 (1981) 877. (b) Adv. Colloid Interface Sci., 17 (1982) 275.

(16) KERN, F., ZANA, R., CANDAU, S.J., Langmuir 7 (1991) 1344.

(17) KERN, F., LEMARECHAL, CANDAU, S.J., CATES, M.E., Langmuir 8 (1992) 437.

(18) BLANKSCHTEIN, D., THURSTON, G., BENEDEK, G., J. Chem. Phys. 85 (1986) 7268, and references therein.

(19) SAFRAN, S., TURKEVITCH, L., PINCUS, P., J. Phys. Lett. 42 (1984) 1135.

(20) MESSAGER, R., OTT, A., CHATENAY, D., URBACH, W., LANGEVIN, D., Phys. Rev. Lett. 60 (1988) 1410.

(21) SAFRAN, S., PINCUS, P.A., CATES, M.E., MACKINTOSH, F., J. Phys. (Paris) 51 (1990) 503.

(22) APPELl, J., PORTE, G., KHATORY, A., KERN, F., CANDAU, S.J., J. Phys. (France) II, 2 (1992) 1045. 
(23) PORTE, G., GOMATI, R., El haITAMI, O., APPELL, J., MARIGNAN, J., J. Phys. Chem. 90 (1986) 5746.

(24) CATES, M.E., DRYE, T.J. (1992) preprint.

(25) PORTE, G., in "Surfactants in Solution", Mittal, K.L., Lindman, B. Eds, Plenum : New York (1984), 805.

(26) ODIJK, T., J. Phys. Chem. 93 (1989) 3688.

(27) ADAM, M., DELSANTI, M., J. Phys 44 (1985) 1185.

(28) LEQUEUX, F., submitted to Europhys. Lett.

(29) SNABRE P., PORTE, G., Europhys. Lett. 13 (1990) 641.

(30) IMAE, T., ABE, A., IKEDA, S., J. Phys. Chem. 92 (1988) 1548.

(31) CANDAU, S.J., HIRSCH, E., ZANA, R., ADAM, M., J. Colloid Interface Sci., 122 (1988) 430.

(32) GRANEK, R., CATES, M.E., J. Chem. Phys., to be published.

(33) OlSSON, U., SÖDERMAN, O., GUERING, P., J. Phys. Chem. 90 (1986) 5223.

(34) KHATORY A., APPELL J., private communication. 